\title{
Addressing the needs of vulnerable road users: application of road safety auditing in New South Wales (Australia)
}

\author{
T. G. Winning \& S. R. Park \\ Winning Traffic Solutions Pty Ltd, Australia
}

\begin{abstract}
The practice of road safety auditing has become an important tool in the prevention of road accidents in New South Wales since its formalisation in the early 1990's. While there is considerable emphasis placed on the role of road safety audits at the concept and design stages (thus facilitating the identification of potential safety hazards long before the road or traffic facility has been built), there has been growing recognition of the role of thematic road safety audits in assessing risks to specific road users. Audits of "School zones" (designated low speed education precincts) focus on the movement needs of children, parents and teachers, assess integration of public transport and identify conflicts with vehicular through traffic. Work zone audits assess the dangers to the occupational health and safety of road workers, the hazards of temporary travel paths and the effectiveness of temporary traffic control in reducing accident risk. Principles of safe traffic integration for vulnerable road users are identified from audit experience and the benefit of thematic road safety audit programs concluded.
\end{abstract}

Keywords: road safety audit, school zones, work site safety, temporary traffic control, vulnerable road users.

\section{Introduction}

The practice of road safety auditing, assessing the road environment for unsafe characteristics as opposed to simply checking for conformance to standards, has become an important tool in the prevention of road accidents in New South Wales (NSW) since its inception in the early 1990's. 
Road Safety Audits are a formal review process focused purely on safety issues. Guidelines for conduct are established Australia-wide by Austroads [1] (the national association of road transport and traffic authorities in Australasia) and in NSW by the Roads and Traffic Authority [2]. A database of qualified auditors and their audit experience is independently maintained by the Institute of Public Works Engineers of Australia (IPWEA) [3].

While there is considerable emphasis placed on the role of road safety audits at the concept and design stages (thus facilitating the identification of potential safety hazards long before the road or traffic facility has been built), there has been growing recognition of the role of thematic road safety audits.

Thematic road safety audits examine specific facilities in the road environment (such as delineation devices, crash barriers or clear zones) or concentrate on the perspective of specific vulnerable user groups (such as children, cyclists, the elderly or the disabled).

In NSW a number of specific road safety initiatives have been demonstrated to benefit in implementation and on-going enhancement from thematic audit attention. This paper concentrates on two such initiatives to demonstrate the application.

\section{Background to the initiatives}

\subsection{School zones}

Vehicle speed has been recognised as a major road safety problem for many years. Accidents involving young children in particular are emotive and politically sensitive. In 1992 the NSW government began installing designated $40 \mathrm{kph}$ speed zones around schools where there were accident histories. In $2002 \mathrm{a}$ large number of additional installations were completed to provide school zones around all primary schools in the state.

School zone speeds are in effect during times of peak pupil and parent movement ( 8.00 to $9.30 \mathrm{am}$ and 2.30 to $4.00 \mathrm{pm}$ school days). In addition to signage and delineation, various traffic calming techniques and devices are also introduced to the built environment to reinforce the speed designation, provide a "signature" to a changed road environment and improve movements through known areas of conflict with vehicular traffic.

These include:

- Kerb extensions and road narrowing

- Raised crossings (known as wombat crossings to clearly differentiate them from zebra crossings)

- School bus bays

- $\quad$ Off-road pick up and drop off zones (also known as kiss and ride spots)

\subsection{Work zones}

Occupational health and safety of road workers and safety of road users are the objective of the NSW Roads and Traffic Authority's approach to traffic 
management of maintenance and construction activity, which has been undertaken for many years in accordance with a definitive manual [4], supported by a tiered training and certification program for road workers and planners.

However moves to privatisation of road infrastructure and third party construction has provided impetus for increased vigilance on conformance. As a condition of contract, road builders undertaking major works are now required to obtain independent work zone audits within 48 hours of making changes to traffic movement.

Traffic Control Safety Audits are consistent with the principles of continuous improvement. The overriding objective of a traffic control safety audit in relation to work sites is to insure they operate as safely as possible.

\section{Audit approach}

A road safety audit is a series of formal checks of road and traffic works, both existing and future, in relation to their accident potential and safety performance for ALL road users. It is conducted by a team independent to the project who can provide an objective safety assessment. The purpose of this audit process is to pro-actively manage road safety by identifying and addressing risks associated with road safety deficiencies.

Thematic audits of "School Zones" focus on the movement needs of children, parents and teachers, assess integration of public transport and identify conflicts with vehicular through traffic.

Work zones audits assess the dangers to the occupational health and safety of road workers, the hazards of temporary travel paths and the effectiveness of temporary traffic control in reducing accident risk.

In both cases, on site inspections are carried out under day and night conditions, on foot and by vehicle, in all directions including the interfacing adjoining road network.

\section{Examples of safety deficiencies identified in audit experience}

\subsection{School zones}

- Vehicles exceeding the designated speed

- Pedestrians crossing randomly i.e. not at designated crossings

- Insufficient designated crossings to cater for pedestrian movement and desire lines

- Poor connectivity of footways and crossings

- Signs, poles and other obstructions to pedestrian movement

- Poorly located school zone boundaries e.g. lack of sight distance, inadequate advance warning

- $\quad$ Signs obscured by foliage or graffiti 
- Driver (parent/guardian) behavior such as unsafe U-turning, right turning and/or overtaking manoeuvres, double parking, allowing children to access vehicles from the roadway side

- Sight distance restrictions to school vehicular driveways on exit

- Insufficient parking/vehicle storage for peak demand

- Queuing and consequential impacts on the road network from school activity

- Inadequate lighting

\subsection{Work zones}

- Incomplete or misleading inputs to traffic management plans

- Inadequate definition of the work zone for driver awareness

- $\quad$ Poor vehicle speed management

- Inappropriate or missing regulatory, warning and advisory signs

- Insufficient distance between road workers and traffic paths

- Unsafe use of temporary barriers (used in isolation or as delineation devices, water-filled barriers without water, barriers over-lapped or set in spear-like configuration)

- Inadequate delineation of the roadway and travel paths (leading to vehicles taking incorrect paths and then improper corrective action)

- Inadequate work site security to deter pedestrian or vehicle access

- Inadequate provision for safe pedestrian movement

- Unsafe access to adjacent land use

- Poorly located construction access points

- Queuing caused by construction activity or incorrectly phased traffic movements

\section{Deduced principles of safe traffic integration for vulnerable road users}

\subsection{Engineering alone may not achieve objectives}

Education and Enforcement are frequently required for initiatives to be successful. In the case of school zones, despite advertising designed to ensure that the public clearly understand the designation, driver compliance with speed limits in 2002 was low. In 2003 the NSW Roads And Traffic Authority commenced a trial of fixed speed cameras. This demonstrated a pronounced and sustained impact on mean speeds over a 12 month period [5].

Awareness and appreciation of the inherent dangers of proximity in work zones (drivers to other drivers, drivers to workers) needs to be constantly reinforced to ensure that traffic control devices receive adequate respect, attention and the appropriate responses. 


\subsection{Initiatives need to be tailored on a case by case basis}

As designated, boundaries for school zones are established based on the perimeter property boundaries of the schools. Audits demonstrate boundaries may need to be extended to provide adequate sight lines for motorists. In some instances boundaries need to encompass adjoining streets to properly service school pedestrian desire lines.

Work site activity can be static (as in the case of construction) or moving (linemarking, road patching etc.). On site conditions are unique and constantly changing. This requires appropriate and updated information to be conveyed to drivers so that they are aware they are approaching (and in) a changed (and less than optimal) environment.

\subsection{Infrastructure needs to be effectively integrated}

Within the identified zone (and at transition and connecting points) integration is essential for such zones to be effective for vulnerable users - adjoining road network, footway connectivity, footway width, footway condition, roadside furniture, pram ramps, signpost placement, and lighting all need to be considered.

\subsection{Devices need to be used in accordance with manufacturer specifications and best practice}

Water filled barriers without water do not provide protection. Concrete barriers should not be splayed to oncoming traffic. Signs sizes and sign spacing need to be adjusted relative to approach speed.

\subsection{Regular maintenance is required}

Not only do signs need to be appropriately located and visible, they need to be clear of landscaping growth and graffiti. In work zones signs easily get moved or knocked over. Traffic signal lanterns fail and variable message boards become misaligned. In all cases regular review and maintenance of signs and devices are mandatory to ensure safety of road users.

\subsection{Special zones are not limited to the targeted users or at targeted times}

Special zones are effective in addressing the needs of vulnerable road users but they also need to be effective for the large majority of potential users and at other times. Safety of non-school pedestrians using school zone crossings outside school hours must be considered. Safety considerations at work zones do not cease when workers leave for the night (or day).

\subsection{Treatments need to be consistent and correct}

Drivers look for visual reinforcement in their assessment of the driving task. It is observed that if they see school premises and children, they are more likely to 
comply with school zone limits. Conversely, the absence of such reinforcement appears to reduce the likelihood of compliance.

Drivers appear to lose respect for signs which are used incorrectly or when they perceive that the message being conveyed (Roadwork Ahead) is not occurring because of the absence of workers.

\section{Conclusion}

Road safety audit programs encourage pro-active risk management. They heighten the awareness of the administrators and managers involved in safety issues generally and the potential impact of safety deficiencies specifically. The road safety audit process confronts complacency with existing conditions and identifies situations where expediency may be prevailing over safety considerations. Thematic audits provide specific and relevant input material to the stakeholders involved so as to facilitate corrective action and thereby minimise the exposure of road users to potentially unsafe elements of the road and the road environment.

\section{References}

[1] AustRoads "Road Safety Audit" Manual, Second Edition 2002

[2] Roads \& Traffic Authority of NSW "Accident Prevention Guide Part 2 Road Safety Audits", August 2005

[3] Institute of Public Works Engineers Association reference website www.roadsafetyauditors.com

[4] Roads \& Traffic Authority of NSW "Traffic Control at Work Sites" Manual, Version 3.1, September 2003

[5] P. Roper \& M. Tziotis, "Evaluation of speed cameras in $40 \mathrm{~km} / \mathrm{h}$ school speed zones", ARRB Group Pty Ltd, March 2005 